\title{
HYDRODYNAMIC INTERACTIONS BETWEEN SHIPS IN NARROW CHANNELS
}

\author{
Vytautas Paulauskas, Donatas Paulauskas, Ričardas Maksimavičius, Martynas Jonkus \\ Dept of Shipping, Klaipeda University, Lithuania
}

Submitted 20 August 2013; resubmitted 12 October 2013; accepted 12 December 2013

\begin{abstract}
Hydrodynamic interactions between ships in narrow channels are important for studying purposes and practical tasks. The paper presents a theoretical basis for the interaction between ships in narrow channels to evaluate reciprocal actions between ships, the experimental results of real ships and data received applying calibrated simulators. The theory and experimental results displayed in the paper could be used for designing channels and evaluating navigational safety in narrow channels as well as for ship steering tasks in narrow channels.
\end{abstract}

Keywords: navigational channels; hydrodynamic interaction; ships; navigation; narrow channels; safe distance.

Reference to this paper should be made as follows: Paulauskas, V.; Paulauskas, D.; Maksimavičius, R.; Jonkus, M. 2014. Hydrodynamic interactions between ships in narrow channels, Transport 29(2): 212-216.

http://dx.doi.org/10.3846/16484142.2014.931886

\section{Introduction}

In many places worldwide, including waterways and ports, there are a number of narrow channels having bidirectional navigation. Hydrodynamic interactions between ships, together with other influences, especially ship drift, are important to avoid ship accidents and incidents in narrow channels (PIANC 1995; 1997, 2010).

Hydrodynamic interactions between ships are based on pressure distribution around the sailing ship (Islund 2003; Paulauskas, 1999). Simultaneously, deeper investigation into practical implementation possibilities is very important for channel optimization and for improving the navigational safety of ships in narrow channels (Recommendations of the Committee... 2010).

Channel designers, ship masters and pilots' understanding and wide knowledge about hydrodynamic interactions between ships along with correct performed actions could decrease the probability of mistakes in the processes of designing channels and optimizing vessel traffic, which therefore finally should have an influence on ship accidents and reduce occurring incidents.

\section{Navigation in Narrow Channels}

A number of channels and waterways, especially in ports, are very narrow and, at the same time, used for bi-directional navigation. Panama, Kiel, etc. canals and rivers such as the Elbe, Schelde, Seine, including the main ports in Hamburg, Antwerp, Rouen has a width of up to $60 \div 80 \mathrm{~m}$ in some bi-directional navigation places.

Hydrodynamic interactions between ships have a big influence, which must be taken in account for the vessels steering to avoid ship collision or grounding (Gucma, Montewka 2005; Paulauskas 1999, 2010, 2011; Paulauskas, Paulauskas 2009). Also, the interactions between ships together with ship drift, particularly in the case of a perpendicular wind direction, could reach high speeds perpendicular to the direction of the sailing ship; thus, any incorrect actions taken by the ship's master or port pilot could dramatically decrease navigational safety (Fig. 1). Simultaneously, a broad knowledge of the ship crew and correct actions can increase the safety of navigation under such circumstances (Paulauskas et al. 2008).

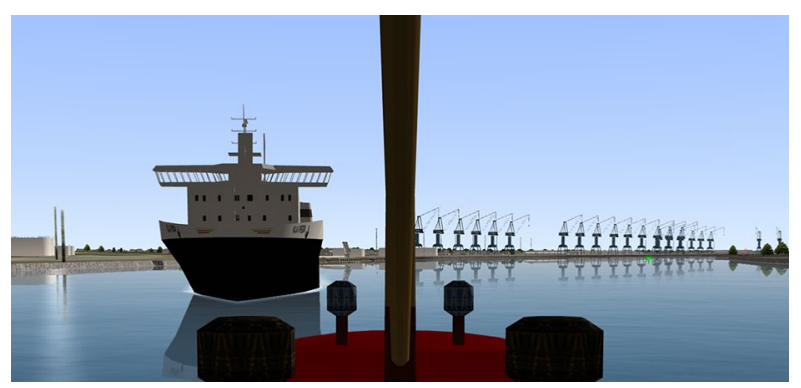

Fig. 1. Ships sailing in narrow channels 
Deep theoretical and experimental studies of the interaction between ships in narrow channels should increase navigational safety in such conditions.

\section{Hydrodynamic Interactions and Other Forces between Ships in Narrow Channels}

Hydrodynamic interactions between ships and other forces that influence ships in narrow channels could be calculated and taken in account for channel design and ship handling. The force of hydrodynamic interactions between ships depends on ship dimensions, speed, distance between the ships and depths in the channel and could be evaluated as follows:

$$
F_{\text {int }}=f(D, v, S, H) \text {, }
$$

where: $D$ - ship's displacement; $v$ - ship's speed; $S$ - distance between the ships; $H$ - depth in the channel.

Ship drift in the narrow channel makes an additional influence on ship trajectory, because in case of a perpendicular wind direction to ships, a ship under wind drift is clause to 0 (Zalewski, Montewka 2007; Vojtkunskij 1985; Fedyaevskij et al. 1982; Paulauskas, Paulauskas 2009). Finally, hydrodynamic interactions between ships and other influences could be explained as follows:

$$
F_{\text {int }}^{\prime}=f\left(D, v, S, H, v_{d}\right),
$$

where: $v_{d}$ - ship drift.

Hydrodynamic interactions between ships based on pressure distribution around the sailing ship are explained in Fig. 2 (Islund 2003).

Revising the case of two sailing ships in the narrow channel, pressure distribution of the ships following opposite directions is shown in Fig. 3, and following parallel directions - in Fig. 4 (Paulauskas 1999, 2010; Fedyaevskij et al. 1982; Paulauskas, Paulauskas 2009).

The forces of hydrodynamic interactions between ships depending on pressure distribution can be expressed in the following way:

$$
F_{\text {int }}=k \cdot\left(D_{1}+D_{2}\right) \cdot\left(v_{1}+v_{2}\right)^{2} \cdot \frac{3 \cdot B}{S^{2}} \cdot \frac{H_{c r}}{H},
$$

where: $k$ - coefficient; $B$ - width of a bigger ship; $H$ depth of the channel; $H_{c r}$ - critical depth in the channel that is calculated as follows:

$$
H_{c r}=\frac{v_{1}}{\sqrt{g \cdot T_{1}}},
$$

where: $T_{1}$ biggest ship's draft; $g$ - gravitational acceleration.

Ship drift can considerably influence ship interaction. In case of a perpendicular wind direction to the ships in the channel, the ships on the side of wind drift could be calculated as follows (Paulauskas, Paulauskas 2009):

$$
v_{d}=v_{a} \cdot \sqrt{\frac{C_{a} \cdot \rho_{1} \cdot S_{x}}{C \cdot \rho \cdot F_{d}}} \cdot \sin q_{a},
$$

where: $v_{a}$ - wind velocity; $q_{a}$ - angle of wind direction; $C_{a}$ - aerodynamic coefficient (could be received in an

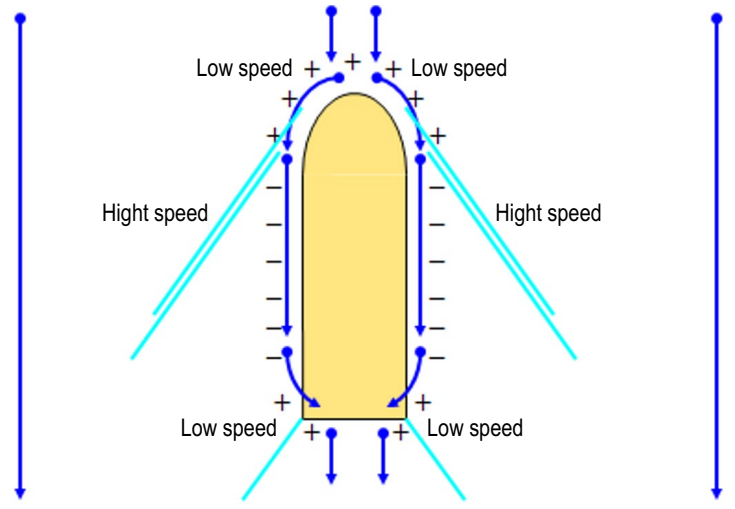

Fig. 2. Pressure distribution around the ship

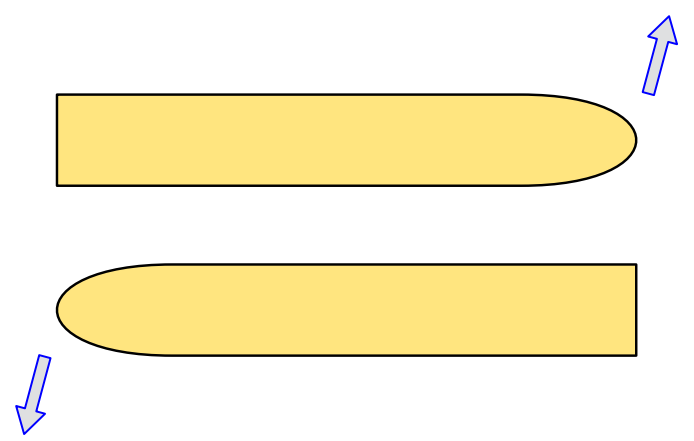

Fig. 3. Pressure distribution of the ships following opposite directions and turning tendencies for ships

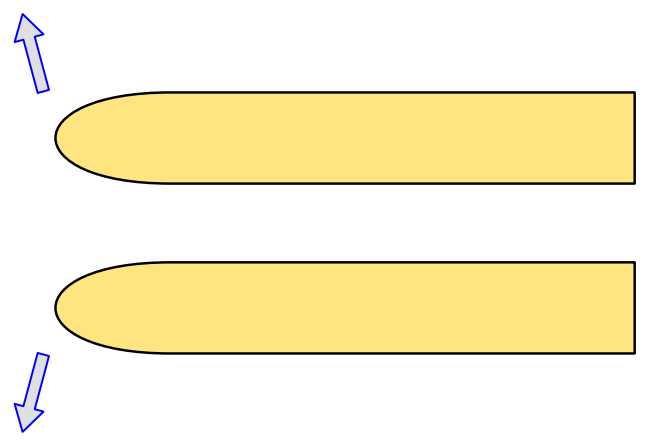

Fig. 4. Pressure distribution of the ships following parallel directions and turning tendencies for ships

aerodynamic testing tube or taken as an average from 1.07 to 1.3 depending on the architecture of decks); $\rho_{1}-$ air density (for calculation purposes could be taken as $\left.1.25 \mathrm{~kg} / \mathrm{m}^{3}\right) ; S_{x}$ - space of projection onto a Diametrical Plane (DP) of the wind surface area (Fedyaevskij et al. 1982); $C$ - hydrodynamic coefficient (could be taken as $1.2 \div 1.5$ depending on the ship construction). For the ships having two or more propellers, the applied coefficient is 1.5 and for other ships - 1.2; $\rho$ - water density (for sea water can be taken from $1015 \mathrm{~kg} / \mathrm{m}^{3}$ up to $1027 \mathrm{~kg} / \mathrm{m}^{3}$ depending on salinity, for fresh water $\left.1000 \mathrm{~kg} / \mathrm{m}^{3}\right) ; F_{d}$ - space of projection onto a DP of the underwater area that can be calculated as:

$$
F_{d}=\varsigma \cdot L \cdot T,
$$

where: $\varsigma$ - square factor (space of projection onto a DP of the underwater area) could be taken from 0.95 up to 
1.0. The maximum value of the coefficient could be applied for the ships having two propellers as well for the ships with a bulb; $L$ - ship's length between perpendiculars; $T$ - average of ship's draft.

Considering the position when ships are near to each other under a perpendicular wind direction to vessels, ship drift on the downwind side could be close to 0 (Fig. 5).

Fig. 5 shows two forces that influence ship interaction in the narrow channel, i.e. forces of hydrodynamic interactions between ships and ship drift on the wind side.

Ship interaction in narrow channels is compensated by force created by the ship rudder. Force momentum created by the ship rudder $M_{p}$ is calculated in the following way (Vojtkunskij 1985):

$$
M_{p}=C_{p} \cdot \frac{\rho}{2} \cdot S_{p} \cdot v^{2} \cdot l_{p}
$$

where: $C_{p}$ - hydrodynamic coefficient of the ship rudder; $S_{p}$ - square of the ship rudder; $l_{p}$ - distance between the ship rudder and ship's pivot point located about $1 / 3$ to the front from the ship's middle frame (Islund 2003), i.e. the last formula can be expressed as follows:

$$
M_{p}=C_{p} \cdot \frac{\rho}{2} \cdot S_{p} \cdot v^{2} \cdot 0.7 \cdot L
$$

The moment of ship turn is created by hydrodynamic interactions acting in the central part of the ship and could be expressed as follows:

$$
M_{\text {int }}=F_{\text {int }} \cdot \frac{L}{3} \text {. }
$$

To follow a straight direction, it is necessary to fulfil the below condition:

$$
M_{p}=M_{\text {int }} \text {. }
$$

Finally, it is possible to receive the maximum rudder angle $\alpha^{\circ}$ that should compensate the hydrodynamic interaction of ships in the narrow channel:

$$
\alpha^{\circ}=\frac{0,174 \cdot\left(D_{1}+D_{2}\right) \cdot\left(v_{1}+v_{2}\right)^{2} B}{\rho \cdot S_{p} \cdot v_{2} \cdot S^{2} \cdot \sqrt{g H}},
$$

where: $S_{p}, v_{2}, D_{2}$ are ship testing parameters.

The received formula points to the opportunity to previously calculate the ship's possibility of protecting hydrodynamic interactions in narrow channels, especially for smaller ships.

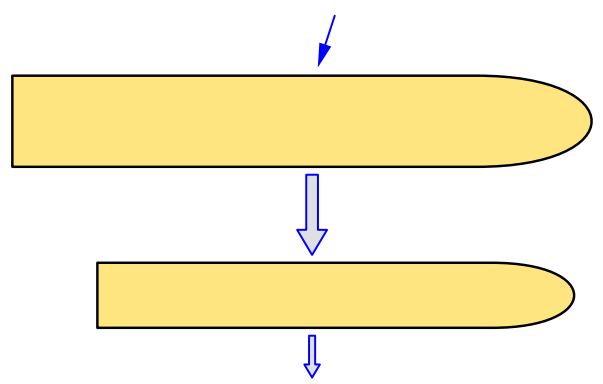

Fig. 5. Ship drift speed under the perpendicular wind direction to ships

\section{Testing Hydrodynamic Interactions on Real Ships and Applying a Simulator}

For testing practical hydrodynamic interactions, Ro-Ro vessels (length $200 \mathrm{~m}$ ) and small coastal ships (length $54 \mathrm{~m}$ ) in the narrow channel were used. The ships were sailing at a distance of up to $15 \mathrm{~m}$ to each other. Both ships were moving at a speed of 6 knots. During testing, weather conditions made no influence, i.e. wind speed was about $6 \mathrm{~m} / \mathrm{s}$, and current velocity reached 0.3 knots.

Ship sailing schemes and some experimental results are presented in Figs 6 and 7. The rudder angle of the ship was calculated with reference to methodological and experimental results received testing real ships.

Experimental and theoretical results show that at the distances shorter than $20 \mathrm{~m}$ for tested ships and under conditions when the speed of a ship is 6 knots, the rudder cannot fully compensate hydrodynamic interactions between ships. For keeping the small ship on course, it is necessary to shortly increase engine power.

On the basis of experimental results, the SimFlex Navigator simulator (E-Sea Fix Manual 2012; SimFlex Navigator 2012; Tomczak 2008) was calibrated for testing hydrodynamic interactions between bigger ships: a PANAMAX loaded tanker and a ferry at different distances between ships and different speeds of the ships in case of wind influence.

Two ships, including the PANAMAX tanker $(L=218 \mathrm{~m} ; B=32.6 \mathrm{~m} ; T=12.5 \mathrm{~m})$ and ferry $(L=$ $150 \mathrm{~m} ; B=23.2 \mathrm{~m} ; T=5.1 \mathrm{~m}$ ) were taken. Testing was made on opposite and parallel courses, wind velocity was $12 \mathrm{~m} / \mathrm{s}$ and a dirrection was perpendicular to that of the ship.

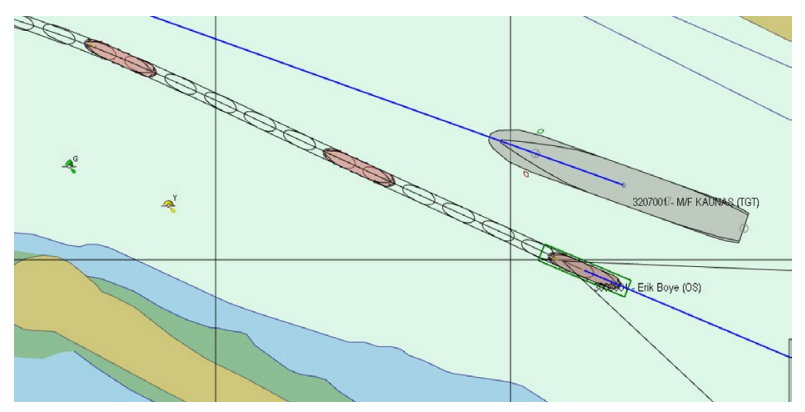

Fig. 6. Scheme for ship sailing in the narrow channel (Ro-Ro and coastal ship)

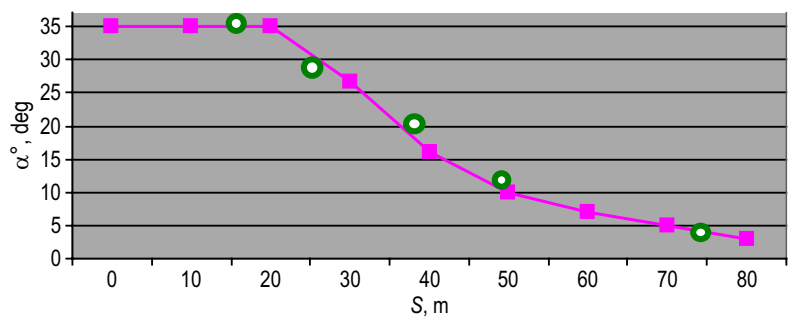

Fig. 7. Hydrodynamic interactions between real ships (Ro-Ro vessel $(L=200 \mathrm{~m})$ and tested coastal ship ( $L=54 \mathrm{~m} ; S_{p}=4.0 \mathrm{~m} ; H=12 \mathrm{~m} ; T=3.5 \mathrm{~m}$ ) (green marks) and theoretical calculation results received using the methodology discussed in the paper 
Ship sailing pictures, schemes and rudder angles to prevent the ferry from yawing are presented in the Figs 8-15.

The hydrodynamic interactions of the ferry Princess Anastasia $(L=177 \mathrm{~m} ; B=29 \mathrm{~m} ; T=6.6 \mathrm{~m}$; displacement $-20000 \mathrm{t}$ ), considering the ships of a similar size in the navigational channel between St.-Petersburg and

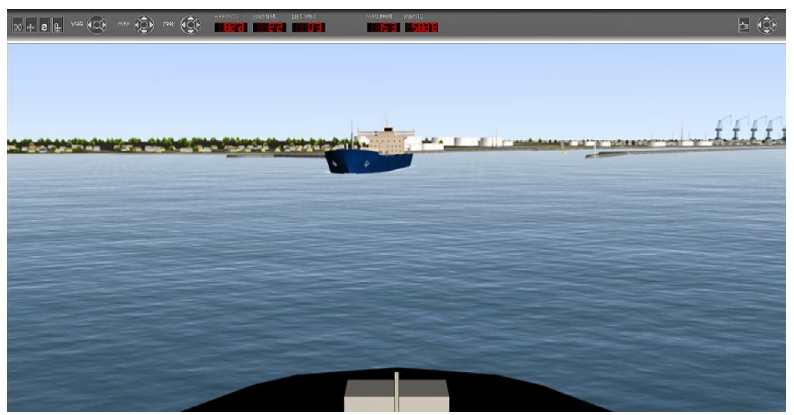

Fig. 8. PANAMAX tanker and a ferry sailing in opposite directions in the port entrance channel

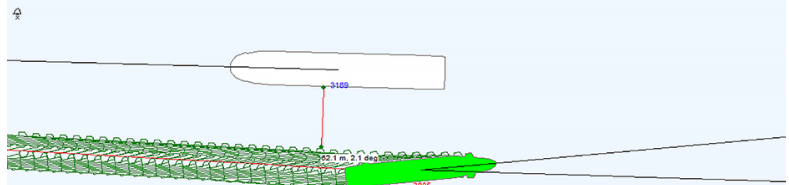

Fig. 9. Scheme for the PANAMAX tanker and a ferry sailing in opposite directions in the port entrance channel and the distance between the ships

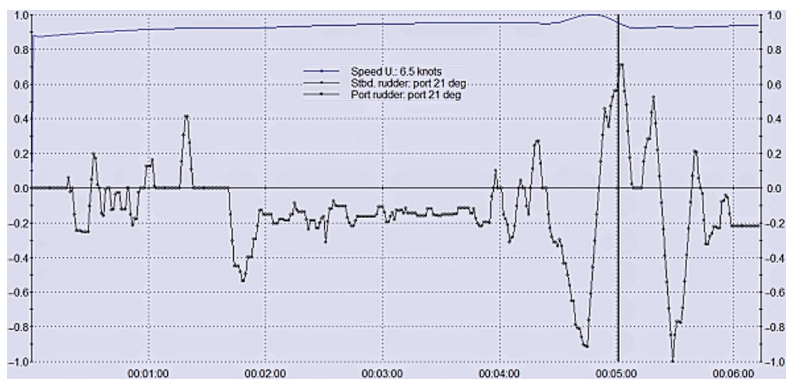

Fig. 10. Hydrodynamic influence between the PANAMAX tanker and a ferry expressed as rudder rotation in the narrow channel in opposite directions (vertical line in the figure corresponds to the ship position indicated in Fig. 9)

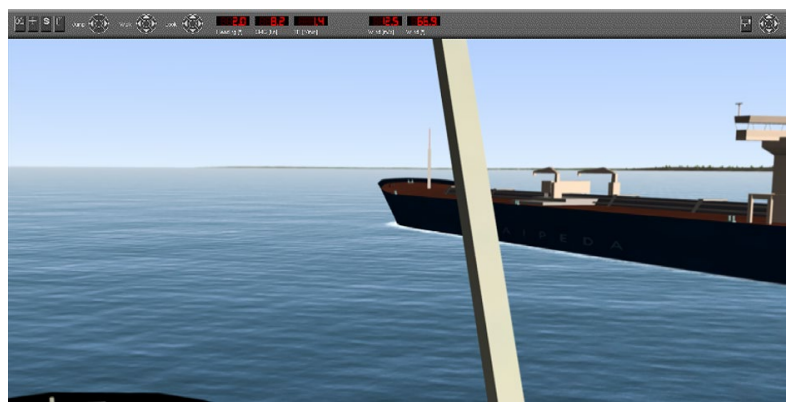

Fig. 11. PANAMAX tanker and a ferry sailing in parallel directions (speed of the PANAMAX tanker is 6 knots, speed of the ferry is 8 knots)
Kronstad as well as in port entrance channels of Helsinki, Stockholm and Tallinn, depending on the distance between the ships, has been received applying the calculation method discussed in the paper (solid line in Fig. 16). Experimental data under real conditions point to a good correlation between the results obtained using theoretical and experimental methods.

Experimental and simulation results show that the theoretical method for calculating the hydrodynamic interaction between ships in narrow channels can be used for practical tasks in designing channels and managing vessel traffic and ship handling.

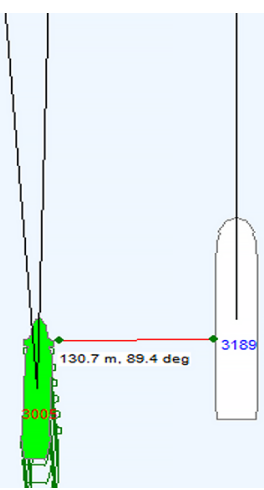

Fig. 12. Scheme for the PANAMAX tanker and a ferry sailing in parallel directions and the distance between the ships (wind direction perpendicular to the courses of the ships, velocity $12 \mathrm{~m} / \mathrm{s}$ )

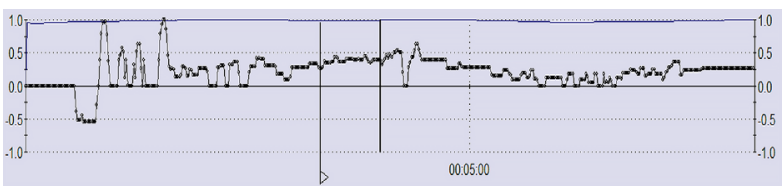

Fig. 13. Hydrodynamic influence between the PANAMAX tanker and a ferry expressed as rudder rotation in the narrow channel in the parallel direction (vertical line in the figure corresponds to the ship position indicated in Fig. 12)

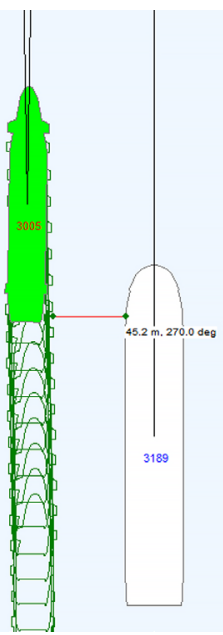

Fig. 14. Scheme for the PANAMAX tanker and a ferry sailing in parallel directions at a very short distance between the ships (wind direction perpendicular to the courses of the ships, velocity $12 \mathrm{~m} / \mathrm{s}$ ) 


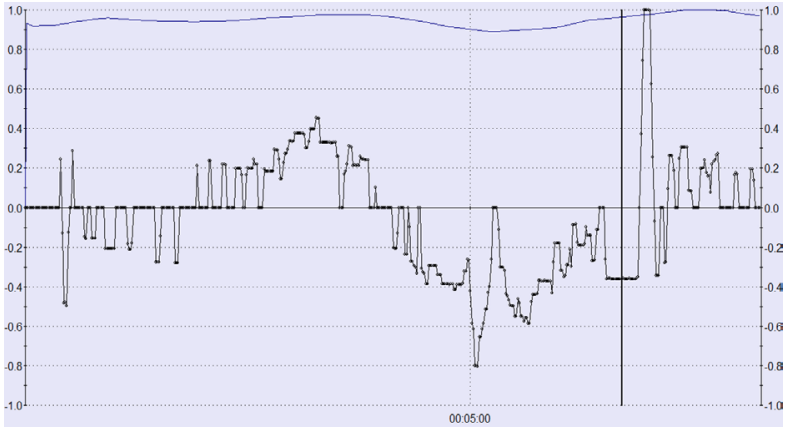

Fig. 15. Hydrodynamic influence between the PANAMAX tanker and a ferry expressed as rudder rotation in the narrow channel in the parallel direction at very short distances (vertical line in the figure corresponds to the ship position indicated in Fig. 14)

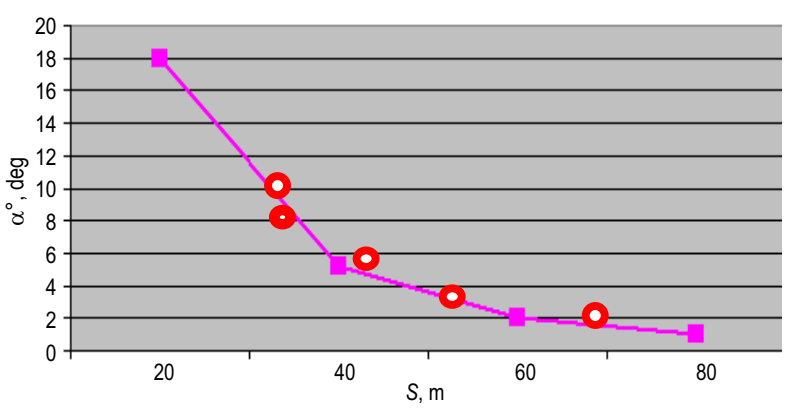

Fig. 16. The results of hydrodynamic interactions between similar sizes of the ships in narrow channels received experimentally on the ferry Princess Anastasia and with reference to calculation results (line)

\section{Conclusions}

Hydrodynamic interactions between ships in narrow channels must be taken into account when designing narrow channels, preparing conditions for ship sailing and proposing precaution measures for navigational safety.

The presented methodology could be used for establishing channels and ship steering procedures under similar conditions.

Hydrodynamic interactions between ships in narrow channels, i.e. the influence of wind, waves, currents, etc., could be considered for improving ship manoeuvrability and increasing navigational safety in narrow channels.

For enhancing port effectiveness and bi-directional ship movement when approaching ports as well as inside navigational channels, hydrodynamic interactions and influence of other external forces on ships must be accepted, which should facilitate the preparation of navigational rules and conditions in ports.

\section{References}

E-Sea Fix Manual. 2012. Marimatech. Denmark. 85 p.

Fedyaevskij, K. K.; Vojtkunskij, Ya. I.; Fadeev, Yu. I. 1982. Gidromehanika. Leningrad: Sudostroenie. 450 s. (in Russian).

Gucma, L.; Montewka, J. 2005. Landborne laser rangefinder measurements for navigation safety assessment, European Journal of Navigation 3(4): 1-6.
Islund, K. 2003. Ship Manoeuvre Theory. Danish Maritime Institute (DMI), Denmark. 192 p.

Paulauskas, V. 2011. Optimalus uostas: monografija. Klaipėda: Klaipedos universiteto leidykla. 320 p. (in Lithuanian).

Paulauskas, V. 2010. Ships turning basins in ports for big container vessels, Zeszyty Naukowe Akademii Morskiej 20(92): 102-106.

Paulauskas, V. 1999. Laivo valdymas ypatingomis salygomis. Klaipeda: Klaipėdos universiteto leidykla. 164 p. (in Lithuanian).

Paulauskas, V.; Paulauskas, D. 2009. Laivo valdymas uoste. Klaipeda: Klaipèdos universiteto leidykla. 256 p. (in Lithuanian).

Paulauskas, V.; Paulauskas, D.; Wijffels, J. 2008. Ships mooring in Complicated Conditions and possible solutions, in Proceedings of the 12th International Conference 'Transport means', 67-70.

PIANC. 2010. Recommendations on Maritime-Port and Terminal Development.

PIANC. 1997. Approach Channels a Guide to Design. Joint PIANC-IAPH Report. 108 p.

PIANC. 1995. Criteria for Movements of Moored Vessels in Harbours.

Recommendations of the Committee for Waterfront Structures Harbours and Waterways EAU 2004: Digitized and Updated Version 2009 (Digital). 2010. Wiley-VCH Verlag GmbH. $250 \mathrm{p}$.

SimFlex Navigator. 2012. Ship Simulator 2012 Full Version.

Tomczak, A. 2008. Safety evaluation of ship's maneuvers carried out on the basis of integrated navigation systems (INS) indications, Journal of Konbin 4(1): 247-266. http://dx.doi.org/10.2478/v10040-008-0021-y

Vojtkunskij, Ya. I. 1985. Spravochnik po teorii korablya. Tom 3. Sudostroenie. 539 s. (in Russian).

Zalewski, P.; Montewka, J. 2007. Navigation safety assessment in an entrance channel, based on real experiments, in Proceedings of the 12th International Congress of the International Maritime Association of the Mediterranean (IMAM 2007), 2-6 September, 2007, Varna, Bulgaria, 1113-1120. 